\title{
Gonioscopic changes after glaucoma
} surgery

\author{
A. W. SOLLOM \\ Wolverhampton
}

Trantas (1907) made the first recorded observations on the angle of the anterior chamber, which he viewed through an ophthalmoscope while indenting the sclera at the limbus on the opposite side. He introduced the term gonioscopy, and found that a view could be obtained using either direct or indirect ophthalmoscopy. A few years later the first attempt to view the angle through a contact lens was made by Salzmann (1915), but his work was troubled by problems of distortion of the view. Then Koeppe (1920) used a slit lamp in conjunction with a contact lens. His design of lens contained a central pit so that the lens could be secured at this place by the knot of a thin bandage. The next development was the uniocular hand microscope designed by Troncoso (1925), who was able to obtain nearly coaxial illumination. He used this with his own contact lens which was more convex than that designed by Koeppe, giving a higher magnification. These events were summarized by Sugar (1949).

The quality of the view with the first lenses cannot have been comparable with those obtained by modern gonioscopy. The first design on which modern lenses are based was produced by Goldmann (1938). Curran (1920) wrote that the anterior chamber deepened after iridectomy or iridotomy for conditions in which the passage of aqueous was impeded on account of the iris hugging the lens over too large a surface. Then Raeder (1923) proposed the classification of glaucoma into cases with wide and narrow angles. Barkan, Boyle, and Maisler (1936) found the angle to be no longer of functional value in many trephine cases, it being occluded in a large percentage by peripheral angle adhesions. In some of these they believed the adhesion to have followed, and to have resulted from, the trephine procedure rather than to have antedated it. Later glaucoma was divided into trabecular (wide-angle) and iris block (narrow-angle) types (Barkan, I94I). He recorded that after basal excision of the iris a tag of the iris root might remain. The pillars of the coloboma were frequently found to be adherent to the angle wall, or to be entangled in the inner lip of the wound, thus increasing closure of the angle and obstruction. Sugar (1942) stated that the main value of gonioscopy lay in aetiological classification and hence in indications for various operative procedures. He considered that synechiae never formed with a narrow angle except after congestion, and that inclusion of tags of iris after iridectomy was common and was to be desired so that a filtering cicatrix might form. He mentioned the use of postoperative gonioscopy to show (I) why a trephine is blocked; (2) deepening of the anterior chamber after iridectomy; (3) the cleft after cyclodialysis. Peripheral anterior synechiae as a result of surgery received scant mention. He also assessed the trephine operation: $5^{2}$ patients had open angles before operationtwo ( 5 per cent.) remained open, $34(65$ per cent.) were partly closed, and sixteen (30 per cent.) were entirely closed. He also analysed 33 cases with open angles which were treated by iridencleisis: 26 were partly open postoperatively, and in seven the angle was obliterated (Sugar, I94I). 
In the following years the opinion was frequently expressed that after surgery for open angle glaucoma peripheral anterior synechiae were frequently present as the result of postoperative collapse of the anterior chamber (Duke-Elder, I949; Hobbs, I954; Gorip and Posner, I957; Stallard, 1958; Becker and Shaffer, I96ı ; Chandler and Grant, I965) This led to the suggestion that the anterior chamber should be reformed if it stayed flat for days (Chandler and Grant, I965), 7 days (Becker and Shaffer, I96I), or 2 weeks (Scheie 1964). Then Allen (1966) observed with the gonioscope 34 eyes which had a shallow on flat anterior chamber after glaucoma surgery and found that thirty had no peripherad anterior synechiae.

A search of the literature over the last 20 years has failed to reveal any detailed analysis to support the views mentioned above which were expressed many years ago, when the angle width had not been classified, the extent of the synechiae was described in terms none, partial, or complete, and the exact duration of the flat anterior chamber was ofter not recorded. In addition, details of the postoperative treatment were often not given and local steroids were not available.

It was therefore decided to study the angle in greater detail, using the classification of angle width suggested by Scheie (1957), who proposed that the grading of angle widtl? depended on the amount of angle structure that could be seen:

Grade o: When the entire angle could be readily seen, including the apex and scleral spura it was classified as wide open.

Grade I narrow: when one could not see over the iris root, but the ciliary body was stil visible.

Grade 2: when the ciliary body could not be seen.

Grade 3 narrow: when the posterior portion of the trabecula was out of sight.

Grade 4: when no structure was visible beyond Schwalbe's line.

Patients were selected from those attending the Birmingham and Midland Eye Hospitaß with uncomplicated glaucoma. The criteria for inclusion in the study were that the angle of the anterior chamber was seen to be open before operation, and that only a single opera: tion was performed.

\section{Findings}

A total of ${ }_{1} 5^{8}$ patients was included in the study and this was made up of 79 periphera iridectomies, 54 Scheie operations, sixteen iridencleises, and nine Scheie operations com bined with peripheral iris inclusion. In the course of seeing these patients insufficiente material became available to study the effect of either broad iridectomy or trephine opera tions.

\section{(1) Peripheral iridectomy (79 cases)}

A comparison of the angle before and after surgery showed the expected widening (Table I). Gonio은 scopy revealed that, of these 79 cases, 22 had tags of iris included in the section (28 per cent.), and $3 \bigoplus_{2}^{\infty}$ had peripheral anterior synechiae covering the trabecular meshwork ( 45 per cent.). It was also found that fifteen cases had some degree of posterior synechia (19 per cent.), and only four of theset had not received a postoperative mydriatic. Several of the patients had suffered a recent attack of acute angle-closure glaucoma, and seventeen had an acute attack within the week before surgery $\overrightarrow{\mathbb{Q}}$ Peripheral anterior synechiae were seen after surgery in seven of these cases ( $4^{\mathrm{I}}$ per cent.). This io 
Table I Alteration in the anterior chamber angle after peripheral iridectomy

\begin{tabular}{lrrrrrr}
\hline Grade of angle & 0 & 1 & 2 & 3 & 4 & Total cases \\
\hline Before surgery & 0 & 0 & 6 & 43 & 30 & 79 \\
After surgery & 12 & 42 & 21 & 2 & 2 & 79 \\
\hline
\end{tabular}

almost the same proportion as in the patients undergoing a prophylactic iridectomy, which suggests that there is no useful benefit in delaying surgery for more than a few days. The extent of the peripheral anterior synechia formation was estimated as a percentage of the angle, and the 36 cases with peripheral anterior synechiae showed the distribution seen in Table II.

Table II Extent of peripheral anterior synechiae after peripheral iridectomy

\begin{tabular}{lllllll}
\hline Percentage peripheral anterior synechiae & $0-20$ & $25-40$ & $45^{-60}$ & $65^{-80}$ & $85^{-100}$ & Total \\
\hline No. of cases & 23 & 8 & 3 & 1 & 1 & 36 \\
\hline
\end{tabular}

As the patients were attending hospital under the care of different members of the staff, there were some variations in the postoperative medication for the operated eye. An attempt was made to determine whether this was an important factor in the development of peripheral anterior synechiae. Eighteen patients received both mydriatic and steroid in the postoperative period, and twelve of these had no peripheral anterior synechiae; the overall average extent of synechia was 3 per cent. 32 patients received a mydriatic alone, and of these sixteen had no peripheral anterior synechiae but the overall extent of synechia was 12 per cent. Six patients were treated with steroid alone; two had no peripheral anterior synechiae but the average extent was 26 per cent.

These figures seem to indicate that the combination of topical mydriatic and steroid gives rise to the lowest amount of peripheral anterior synechiae. However 23 patients received neither mydriatic nor steroid, and of these twelve had no peripheral anterior synechiae, and the group showed an average extent of only 7 per cent. This appears slightly better than the results with a mydriatic alone, but it is not so satisfactory as the combination of mydriatic and steroid.

In this group three patients possessed a draining bleb; in none of these was iris included in the section. Six iridectomies were not peripheral.

Two patients developed a flat anterior chamber which lasted I and 3 days (with o and 30 per cent. peripheral anterior synechiae respectively), and three patients had a shallow anterior chamber lasting 2,4 , and 9 days (with o, Io, and 5 per cent. peripheral anterior synechiae respectively).

\section{(2) Scheie's operation (54 cases)}

This fistulizing operation was performed on 54 patients and only nine had no peripheral anterior synechiae afterwards. Half of this group (27 patients) had a flat anterior chamber which was present for $\mathrm{I}$ to Io days and recovered without surgical intervention. A draining bleb developed in 39 cases and although fifteen patients had no visible evidence of drainage there were only four in the series in whom the intraocular pressure was not reduced to normal after surgery. Seventeen showed inclusion of the iris in the incision when it was not intended. Eighteen patients showed posterior synechiae, of whom five had received no postoperative mydriatic.

There were 45 patients who developed peripheral anterior synechiae and it has been stated above that these should be related to the duration of flat anterior chamber. The 27 who did not have a flat anterior chamber at any time after surgery were analysed, to investigate this. They showed peripheral anterior synechiae in many instances and the extent is compared with that in the other group of patients who had suffered a flat anterior chamber in Table III (overleaf). 
Table III Effect of flat anterior chamber on peripheral anterior synechiae after Scheie's operation

\begin{tabular}{|c|c|c|c|c|c|c|c|}
\hline \multicolumn{2}{|c|}{ Percentage peripheral anterior synechiae } & $0-20$ & $25-40$ & $45^{-6 o}$ & $65-80$ & $85^{-100}$ & \\
\hline \multirow{2}{*}{ Anterior chamber } & Good & I 6 & 6 & 2 & 2 & I & 27 \\
\hline & Flat & I I & 4 & 5 & 5 & 2 & 27 \\
\hline
\end{tabular}

This shows that a greater amount of peripheral anterior synechiae is to be expected if the anterio? chamber is flat postoperatively. However, if both sets of figures are put together in a scattergranf which also shows the duration of the flat anterior chamber, there appears to be no trend of increasing peripheral anterior synechiae associated with increasing duration of the flat anterior chamber. The distribution of peripheral anterior synechiae in those cases which maintained a good anterior chambe can also be seen (Table IV).

Table IV Extent of peripheral anterior synechiae related to duration of flat anterior chambe $\mathrm{L}_{0}$ (27 cases) compared with those with good anterior chamber (27 cases)

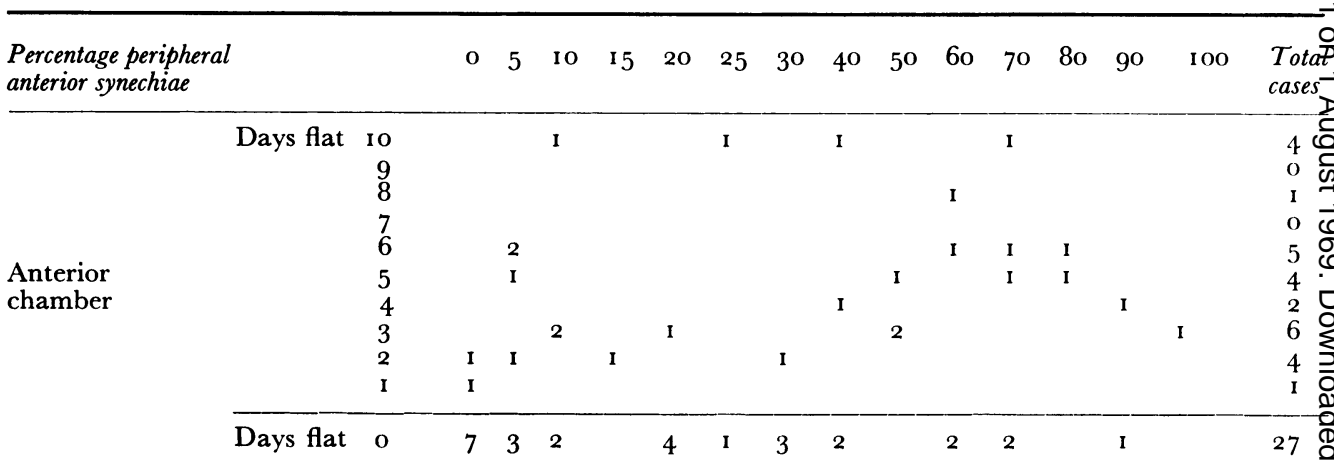

A further study of the series in an attempt to determine a reason for the development of peripherat anterior synechiae which were not anticipated on account of a flat anterior chamber, revealed a unexpected finding. It became apparent that, in the 27 cases which did not have a flat anterio chamber, the extent of the peripheral anterior synechiae after surgery was related to the preoperative width of the chamber angle (Table $\mathrm{V}$ ).

Table $\mathbf{V}$ Peripheral anterior synechiae related to preoperative angle width (anterior chamber maintained)

\begin{tabular}{|c|c|c|c|c|c|c|}
\hline Preoperative grade & o & I & 2 & 3 & 4 & Total \\
\hline Number of cases & 8 & 4 & 5 & 7 & 3 & 27 \\
\hline $\begin{array}{l}\text { Percentage of angle occluded } \\
\text { by peripheral anterior } \\
\text { synechiae (average) }\end{array}$ & 9 & I6 & I I & 46 & 47 & - \\
\hline
\end{tabular}

This suggests that a narrow angle predisposes to the formation of peripheral anterior synechiao and this is confirmed when the patients who developed a flat anterior chamber are analysed (Table VI, opposite).

Ten patients with Grades o and I had 50 per cent. peripheral anterior synechiae or less, and only had more than 50 per cent. Further evidence to support this is found when the complete series of 5 范 cases is studied (Table VII, opposite). 
Table VI Grade of preoperative angle and development of peripheral anterior synechiae (with loss of anterior chamber)

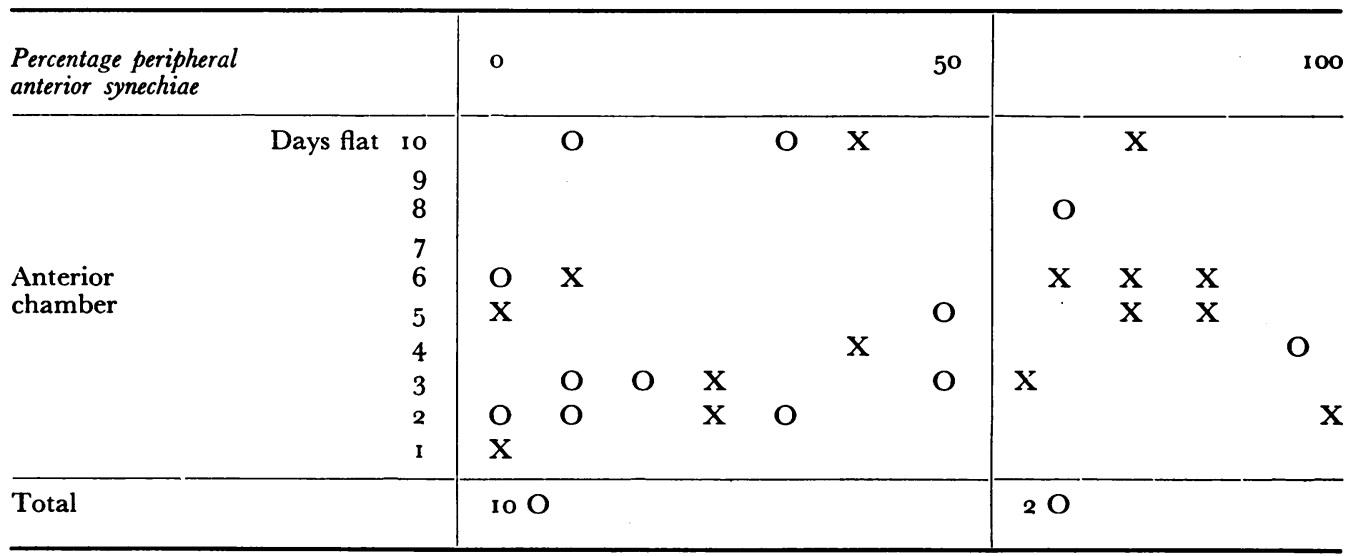

$\mathrm{O}=$ Grades o and $\mathrm{I} \quad \mathrm{X}=$ Grades 2, 3, and 4

Table VII Preoperative grade of angle related to development of peripheral anterior synechiae in all 54 cases

\begin{tabular}{lrrrrrr}
\hline Preoperative grade & 0 & 1 & 2 & 3 & 4 & Total \\
\hline Number of cases & 16 & 8 & 11 & 14 & 5 & 54 \\
\hline $\begin{array}{l}\text { Percentage of angle occluded } \\
\text { synechipheral anterior }\end{array}$ & 18 & 25 & 33 & 43 & 50 & \\
\hline \begin{tabular}{l} 
synerage) \\
\hline
\end{tabular} & & & & & & \\
\hline
\end{tabular}

This group was also analysed to determine whether the postoperative topical application of mydriatic and steroid (alone or combined) affected the extent of peripheral anterior synechiae. The combination of mydriatic and steroid was associated with the least peripheral anterior synechiae but different treatment was only slightly worse. The number in each group is small and these results may not be significant. Gonioscopy also revealed that only two of the iridectomies were not peripheral, and one was incomplete.

\section{(3) Iridencleisis ( 16 cases)}

Only one case did not develop some peripheral anterior synechiae. No flat anterior chambers occurred. Again the peripheral anterior synechiae appeared to be related to the preoperative chamber angle width. With Grade o there were 6 per cent. peripheral anterior synechiae on average, and with Grade 470 per cent. Some patients who received neither mydriatic nor steroids after surgery showed very few signs of previous inflammation, but as a group those who did receive this treatment had the least abnormal findings.

\section{(4) Scheie's operation with peripheral iris inclusion (9 cases)}

All those with Grade $o$ and I angles maintained the anterior chamber after surgery, and none developed peripheral anterior synechiae, but all those with Grades 3 and 4 suffered a flat anterior chamber and all developed peripheral anterior synechiae, average 33 per cent. In eight of the nine patients the tension was controlled and this procedure may be worthy of further study so that more useful conclusions can be obtained. 


\section{Discussion}

All the patients subjected to peripheral iridectomy had narrow angles, so that a comparison of angle width and postoperative peripheral anterior synechiae could not be carried ou $\overrightarrow{\mathrm{E}}$ Almost half developed some peripheral anterior synechiae, but the average extent was onlo Io per cent. Only one-fifth developed posterior synechiae, and these were not associate with extensive peripheral anterior synechiae. No relationship between these two inflam $\bar{s}$ matory signs could be found. It appeared that the peripheral anterior synechiae can b® reduced by a postoperative topical mydriatic and steroid, which is in accord with currenê thought. There was somewhat contradictory evidence that the use of a mydriatic alone्P did not bring any substantial benefit to the eye. The individual variation was such that three patients had very extensive peripheral anterior synechiae which affect the average results. When a drainage operation is performed there is evidence from this series as wet that the use of a topical mydriatic and steroid is effective in reducing the signs of inflame mation as evidenced by the presence of iridocorneal adhesions in the angle. One-third of the patients showed posterior synechiae after Scheie's operation, and four out of five ha peripheral anterior synechiae. Again the two signs did not seem to be related. It may be that topical medication is able to reduce and almost prevent the slight traumatic uveitis resulting from a peripheral iridectomy, but is insufficient to prevent inflammatory signs after a more irritating procedure.

A relationship between the angle width and postoperative peripheral anterior synechiae does not seem to have been considered previously. The condition has been described i. greater detail after cataract surgery than in connexion with drainage procedures. If the angle width is an important factor in the development of peripheral anterior synechiae this would go some way towards explaining the variation in opinion of different authoritie with regard to the seriousness of, and therefore need to interfere with, a flat anteriof chamber. There is no doubt that, besides the formation of peripheral anterior synechiae, there are other dangers such as lens damage when the anterior chamber is collapsed, an that it is an undesirable event. This work shows that peripheral anterior synechiae are only slightly increased by a flat anterior chamber and that they are moderately common even when the anterior chamber remains well formed, but that a more important factor in their development is the angle width.

\section{Summary}

I 58 patients were examined after various surgical procedures to relieve glaucoma, and high proportion were found to have developed peripheral anterior synechiae. It appearec that these were commoner when the angle was narrow before operation and that this was more important factor than a temporary postoperative flat anterior chamber.

I wish to thank the members of the staff of the Birmingham and Midland Eye Hospital for their help in this work, and for permitting me to see their patients.

\section{References}

Allen, J. C. (1966) Amer. 7. Ophthal., 62, 509

BARKAN, O. (1941) Ibid., 24, 768

, BOYLE, S. F., and MAISLER, S. (1936) Ibid., 19, 209

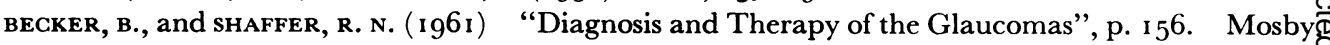

St. Louis 
CHANDleR, P. A., and GRANT, w. M. (1965) "Lectures on Glaucoma", p. 98. Kimpton, London;

Lea and Febiger, Philadelphia

GURRAN, E. J. (1920) Arch. Ophthal. (N.Y.), 49, 131

DUKe-ELder, s. (1949) Arch. Ophthal. (Chicago), 42, 538

GoldmanN, H. (1938) Ophthalmologica (Basel), 96, 90

GORIN, G., and POSNER, A. (1957) "Slit Lamp Gonioscopy", p. 125. Williams and Wilkins,

Baltimore

новвS, н. Е. (1954) Trans. ophthal. Soc. U.K., 74, I 53

KOEPPE, L. (1920) v. Graefes Arch. Ophthal., 101, 48

RAEDER, J. G. (I923) Ibid., I12, 29

salzmann, м. (1915) Z. Augenheilk., 34, i6o

scheie, H. G. (1957) A.M.A. Arch. Ophthal., 58, 5 Io

(1964) Trans. ophthal. Soc. U.K., 84, I 27

StAllard, H. B. (1958) “Eye Surgery”, 3rd ed., p. 6oo. Wright, Bristol

SUGAR, H. S. (194I) Arch. Ophthal. (Chicago), 25, 674

(1942) Amer. F. Ophthal., 25, 663

( I949) "Gonioscopy", in "Biomicroscopy of the Eye", ed. M. L. Berliner, pp. 598-655.

Hoeber, New York

trantas, A. (1907) Arch. Ophtal. (Paris), 27, 581

troncoso, м. U. (1925) Amer. J. Ophthal., 8, 433 